\title{
PRAGMATIC COMPETENCE INJUSTICE
}

When engaging in verbal communication, we do not simply use language to dispense information, but also to perform a plethora of actions, some of which depend on conventionalised, recurrent linguistic structures. Additionally, we must be skilled enough to arrive at the speaker's intended meaning. However, speakers' performance may deviate from certain habits and expectations concerning the way(s) of speaking or accomplishing actions, while various factors may hinder comprehension, which may give rise to misappraisals of their respective abilities and capacities as competent language users. This paper discusses whether such misappraisals may be subsumed by any of the already identified types of epistemic injustice and proposes a new label for them. It also describes the consequences of those misappraisals and approaches their origins from a cognitive perspective.

Keywords: Pragmatics; Communicative Competence; Pragmatic Competence; Pragmatic Failures; Epistemic Injustice

\section{Introduction}

Over the last past years, notable efforts have been made to identify and characterise various epistemic injustices that individuals may sustain as a consequence of the influence of negative stereotypes and identity prejudice. Initially, Fricker (1998, 2003, 2006, 2007) differentiated two injustices preventing disempowered individuals from being considered knowers in some domain. On the one hand, testimonial injustice, or the wrong done when information is deemed unreliable because of lack of evidence or sound knowledge. On the other hand, hermeneutical injustice, or the unfairness suffered because of inability to make experiences understood due to lack of tools to comprehend and express them (Fricker 2006, 99-101; 2007, 151).

Dotson (2012) subsequently added contributory injustice, or the wrong done by prejudiced individuals who purposefully decide not to understand a marginalised person despite possession of tools facilitating correct understanding and expression of experiences. More 
recently, Anderson (2017a) has described conceptual competence injustice, which is perpetrated when a dominant group considers that someone who does not possess the vocabulary to properly talk about a specific domain lacks the corresponding concepts and, therefore, does not regard her ${ }^{1}$ as a knower or expert in that domain. As the label indicates, this injustice solely affects an area of competence: concept-word mappings (Sperber and Wilson 1997). Perception of communicative performance results in an assessment of the victim as incapable of distinguishing and categorising (nuances in) elements of reality and, therefore, as lacking a sophisticated conceptual repertoire.

Competence in a language is a marker of education and, hence, of credibility. It is evidenced through standardised grammar and appropriate vocabulary (Anderson 2012, 169), but it also hinges on knowledge about when, where, with whom and how to talk about certain issues or use some expressions in order to achieve specific goals (Hymes 1972; Canale 1983; Bachman 1991; Celce-Murcia et al. 1995; Kasper 1997). Speaking a language also requires convergence with other language users, who often make up communities of practice (Wenger 1998), ${ }^{2}$ in terms of conventions constraining the structures needed to express certain intentions, the meaning of some expressions, their usage restrictions and their expectable outcomes. Indeed, convergence helps coordinate behaviour, enables understanding and reduces the likelihood of misunderstanding and social friction (Anderson 2012, 170). But competence in a language, moreover, requires abilities to correctly process and interpret what other people say, and thus arrive at intended messages or speaker's meaning, which are tasks that do not only depend on decoding but also on inference, mindreading or emotion-reading (Sperber and Wilson 1986/1995, 2015; Wilson and Sperber 2002, 2004).

Native speakers are presupposed to be communicatively competent, so adequate performance is taken for granted and goes unnoticed. However, production or 
comprehension failures often occur and impede smooth communication to a greater or lesser extent. Although these are normally resolved and mutual understanding is discursively restored (Dascal 1999), negative conclusions may be drawn about the individual who made a mistake. In fact, in addition to unveiling occasional incompetence because of factors like absentmindedness, tiredness, emotional overdrive or multitasking (Mustajoki 2012), mistakes may reveal more persistent and serious handicaps. If mistakes are frequent or repeated with the same interlocutors, language users may unfortunately be judged -obviously, against their interests- as lacking skilfulness in a relevant area of language, which may negatively impact their reputation as communicators. In contexts where individuals are prejudiced against identities, a judgement like this may be especially dangerous and contribute to their marginalisation as epistemic agents.

This paper seeks to widen our understanding of the phenomenon of epistemic injustice by identifying and characterising a new type connected with another area of communicative competence (Hymes 1972): pragmatics. Since pragmatics subsumes the abilities to speak in a way that is adequate to the social and spatio-temporal context of communication, and to efficiently process linguistic input, this injustice is perpetrated when individuals, regardless of whether they are marginalised, are not understood as expected because they either select semantico-syntactic patterns differing from those that their interlocutors customarily use to verbally accomplish actions, attempt to perform verbal actions in the wrong context or appear to have comprehension problems. This is the injustice that a Peninsular Spanish-speaking student may inflict on a Mexican Spanish-speaking mate if the latter made a request for the former's notes by means of a rather elaborate formula like (1) and the former thought that his Mexican colleague was trying to butter him up to get his notes: 
(1) Disculpa, Juan. Me pregunto si habría alguna posibilidad de que me dejaras tus notas nomás un momentito ahorita mismo.

[Excuse me, John. I wonder whether there would be any chance that you would lend me your notes for just one moment right now]

The injustice in question may also arise when, for example, a shop-assistant notices that a customer is ill and, out of true commiseration and sympathy, enquires whether he is actually ill and recommends him to take a particular medicine, go to the doctor, put on more clothes, stay at home, etc., and her behaviour is unfortunately understood by the customer, as a consequence of a negative bias against the shop-assistant's ethnicity or abidance by differing interactive standards, as unduly motherly or as an intrusion in his privacy. Finally, this sort of injustice may originate when, for instance, an employee fails to understand her boss's request to do something "at some point this morning" as meaning "right now" or "immediately", and the boss doubts the employee's comprehension skills. These (seeming) pragmatic mistakes induce (dominant) individuals to question the pragmatic abilities of (unprivileged) individuals and to think that they are not (fully) competent language users. The identification and characterisation of this injustice purports to contribute to understanding some of the unexpected and/or undesired perlocutionary effects that communicative behaviour may have as a consequence of prejudice.

This paper begins by briefly presenting the major components of communicative competence as a way of appreciating the role of pragmatics in communication (Section 2). Next follows an overview of some threats to communication, namely, real or apparent production and comprehension mistakes, which may result in unfair, unwarranted conclusions about the participant who makes them (Section 3). Then, this paper discusses the suitability of the extant types of epistemic injustice for subsuming a wrong done on the 
grounds of allegedly deficient pragmatic performance (Section 4) and proposes a new label for it (Section 5). Before concluding, a cognitive account is given of the reasons why individuals may wrong others on the basis of their apparently deviating speaking habits and comprehension troubles (Section 6).

\section{Communicative Competence and Pragmatics}

Using language is probably one of the greatest achievements of the human species. Not only do we impart information about the world, but we also perform a plethora of actions -speech acts (Austin 1962; Searle 1969)- fundamental for social interaction: greeting, requesting goods, ordering people to do actions, thanking them for what they (have) do(ne), etc. The ability to use a language for these and other purposes greatly depends on abstract knowledge: langue, in de Saussure's (1916) terms, or competence, in Chomsky's (1965). When put into practice, competence surfaces in perceptible behaviour: parole or performance.

Ever since the influential work by Hymes (1972), the knowledge enabling performance is referred to as communicative competence in diverse fields of linguistics and is conceived of as resting on more specialised subtypes of knowledge. Although these have been labelled differently, suffice to mention the following for the sake of simplicity:

a) Knowledge of vocabulary and grammar rules: grammatical or linguistic competence, which facilitates awareness of the meaning of words, their pronunciation and combination restrictions (Canale 1983; Celce-Murcia et al. 1995). 
b) Knowledge of how to arrange units longer than sentences, manage old and new information and structure discourse: organisational knowledge (Bachman 1991) or discourse competence (Canale 1983; Celce-Murcia et al. 1995).

c) Knowledge of the sociocultural norms or conventions governing the structures to express intentions on the grounds of the setting, the interlocutors' identities, attributes, interactive goals or factors like formality or spoken variety: sociolinguistic competence (Canale 1983), pragmatic knowledge (Bachman 1991), actional and sociocultural competence (Celce-Murcia et al. 1995) or pragmatic competence (Kasper 1997).

While linguistic competence results in production of correct sentences, discourse competence yields well-formed and meaningful texts. Pragmatic competence, in turn, is essential for what speakers say to be contextually adequate. Competence judgements, hence, depend on production of grammatically correct and understandable discourse that fits the interactive context and abides by operating conventions.

Conventionalisation of linguistic structures as vehicles to accomplish specific speech acts greatly determines their acceptability, as well as effortless and straightforward identification of intentions. For instance, in distinct varieties of a pluricentric language like English, structures like "NP [is/looks] (really) ADJ" (2), "I (really) [like/love] NP" (3) and "PRO is (really) (a) ADJ NP" (4) are frequent means to pay compliments and are almost automatically recognised as such (Manes and Wolfson 1981; Wolfson and Manes 1980). ${ }^{3}$ Similarly, structures like "Can/Could/May PRO V NP" $(5,6)$ are conventionalised requests:4

(2) That shirt looks great on you!

(3) I (really) love your new hairdo!

(4) That is a good question. 
(5) Could/Can you pass me the salt (please)?

(6) May I have a glass of water?

Since meaning and usage conventions ease communication and highly condition its success, languages could be said not to exclusively rely on arbitrary associations between meanings signifieds- and lexical items -signifiers (de Saussure 1916)- but also on relatively stable associations between semantico-syntactic structures and intentions. Fundamental though mastery of these associations may be for pragmatic competence, this must be portrayed as a more complex ability, as individuals constantly shift from their role of speakers to that of hearers (Brown 1995). Pragmatic competence, then, should necessarily encompass the skill to interpret utterances correctly.

Comprehension goes well beyond mere decoding. Arriving at speaker's meaning is contingent on a series of simultaneous, subconscious and extremely fast tasks that make up the intricate process of mutual parallel adjustment of explicit and implicit content. These tasks mobilise various automatic and specialised mental mechanisms or modules (Sperber and Wilson 1986/1995; Carston 2002; Wilson and Sperber 2002, 2004; Wilson 2012):

a) The language module, which decodes and minimally parses linguistic input.

b) The inferential module, which assigns reference to expressions like personal pronouns, proper names or deictics; adjusts the denotation of the concepts encoded by some words -e.g. 'lion' in an utterance like "John is a lion", which does not communicate that the person named John is literally a lion, but that he shares some of the properties attributable to lions (fierceness, braveness, etc.)- disambiguates sentential constituents and discourse chunks; recovers elided contents, and accesses and relates information enabling the derivation of certain (expected) conclusions.

c) The mindreading module, which attributes mental states to other individuals. 
d) The emotion-reading module, which recognises the speaker's attitude towards the communicated information and/or her feelings while speaking.

Despite the specialisation of these modules, there is no guarantee that the output of the tasks that they perform -i.e. interpretative hypotheses- is the expected one. Reference may be incorrectly assigned, concepts may be adjusted in the wrong direction, unintended contextual assumptions may be accessed and yield undesired conclusions, etc., so hearers may fail to arrive at speaker's meaning (Yus Ramos 1999a, 1999b). Behaving as a competent hearer involves formulating interpretative hypotheses that match actual speaker's meaning.

Like any other competence, pragmatic competence is comparative and contrastive (Medina 2011 , 18). Communicators may be evaluated as (highly) pragmatically competent in some domain -e.g. making requests, grasping double senses, etc.- but not in others -e.g. expressing gratitude, understanding figurative language or irony, etc.- or as more or less pragmatically competent than other individuals. Additionally, pragmatic competence is also contextdependent and the way in which it surfaces varies across settings and time due to psychological states -e.g. nervousness, concentration, happiness, etc.- physical or physiological conditions -e.g. tiredness, drowsiness, etc.- performance of actions necessary for physiological functions -e.g. swallowing, sipping, sneezing, etc.- or interlocutors and relationships with them (Mustajoki 2012). Finally, pragmatic competence is gradual because it increases as a result of age, maturity, personal experience or factors such as instruction and subsequent learning, needs, interests, motivation, etc. (Padilla Cruz 2017c).

\section{Risks of Communication}


Communication certainly yields many benefits, but it is also fraught with serious difficulties and challenges (Mascaro and Sperber 2009), one of which is misunderstanding. This occurs whenever there is a mismatch between the meaning that the speaker envisaged and what the hearer thinks that she meant (Bazzanella and Damiano 1999; Ryan and Barnard 2009). In addition to non-hearing, mishearing or partially hearing because of disturbances in the channel (Grimshaw 1980), hearers misunderstand because of flaws in mutual parallel adjustment, which result in unintended explicit or implicit contents, missing implications, misattributions of intentions or emotions, or unexpected and/or undesired (re)actions (Bark et al. 1991; Yus Ramos 1999a, 1999b). Moreover, speaker's meaning may not be grasped because of conceptual or lexical deficits, lacunae in belief boxes or storage of false beliefs (Gass and Varonis 1991; Weigand 1999; Ryan and Barnard 2009). Overt or latent failure to correctly understand may give the impression of incompetence (Hinnenkamp 2003, 61-65).

Speakers are also responsible for misunderstanding, as they may not correctly conceptualise intentions, avoid expressing them clearly for a variety of reasons or choose inappropriate utterances to make these manifest (Dua 1990, 115). Mispronunciation, vague or ambiguous vocabulary -polysemous words, placeholders, etc.- ambivalent syntax, lack of coherence or failure to be completely explicit give rise to misstatements, which also hinder understanding (Bark et al. 1991; Bazzanella and Damiano 1999). Although on some occasions misstatements simply amount to slips of the tongue motivated by the said psychological or physiological states (Mustajoki 2012), on other occasions they evidence some degree of incompetence (Ardissono et al. 1998; Dascal 1999; Weigand 1999; Keysar and Henly 2002; Jucker et al. 2003; Ferreira et al. 2005; Keysar 2007; Shintel and Keysar 2009; Verdonik 2010). Two types of production mistakes may particularly threaten communication. Subsumed under the label pragmatic failure, they reveal "[...] inability to understand what is meant by 
what is said" (Thomas 1983, 93). The first one is pragmalinguistic failure and arises when the linguistic structures selected to perform certain speech acts diverge from those conventionalised in a community of practice, upgraders or downtoners ${ }^{5}$ are not used, or inadequate intonation is employed (Thomas 1983; Riley 1989, 2006; Olshtain and Cohen 1990; Tran 2006). Examples would be resorting to an unmitigated imperative when ordering something (7); original, innovative and personal, but unusual, comparisons when complimenting (8); failing to add adverbs like 'really' or 'deeply' when apologising (9) in order to exhibit true regret (Olshtain and Cohen 1990), or using a falling contour (10) instead of a rising one when making an offer (Tannen 1984):

(7) Give me a beer!

(8) You look like the moon rising on the horizon!

(9) I am sorry.

(10) 'Gravy. ${ }^{6}$

The second type is sociopragmatic failure and originates as a consequence of abidance by differing conversational norms or the prominence given to specific ones. This results in utterances or actions that appear as unexpected, dispreferred or non-permitted in a given context. In other words, sociopragmatic failures occur when what is said or done, the addressee, the moment and/or the place are inappropriate. While pragmalinguistic failure is connected with the linguistic form, sociopragmatic failure stems from mismatches between expectations and what is actually said or done, or left unsaid or undone. Examples would be paying a compliment that highlights very personal traits (11) or achievements (12), which may be perceived as ironical (Hickey 1991); not greeting when arriving at a place, or speaking at moments when silence is expected or preferred -e.g. during a religious service (Reynolds 1995): 
(11) You are so polite!

(12) How punctual you are!

Comprehension failures should also count as cases of pragmatic failure insofar as hearers misunderstand speaker's meaning (Padilla Cruz 2013). Quite often, pragmatic failures are not dramatic and their causes are reasoned out (McRoy and Hirst 1995) and joint repair is sought through circumlocution, approximation, repetition, help/clarification questions, replacement of problematic items, slowing down of tempo, assessments or echoic repetitions (Jefferson 1972; Schegloff 1982; Goodwing 1986; Bazzanella and Damiano 1999; Codó Olsina 2002). These are resorted to during grounding, or the discursive process aimed at restoring mutual understanding (Clark and Schaefer 1984; Hinnenkamp 2003).

In other cases, however, pragmatic failures result in puzzlement, astonishment, frustration and anger. Depending on the degree of error or trespass perceived, comprehension flaws and deviations from expected or usual communicative habits may also produce ill-founded attribution of personality traits and attitudes -e.g. boldness, insolence, tactlessness, impoliteness or offensiveness (Fraser 1990; Spencer-Oatey 2000; Eelen 2001)- beliefs or intentions which would allegedly have motivated a behaviour (Field 2007). This very usually happens in cross-cultural contexts. For instance, Polish, Greek, Israeli or Venezuelan immigrants and minorities in some English-speaking countries are often perceived as abrupt, impolite or tactless because, as a result of the influence of their mother tongue, they resort to direct, unmitigated imperatives when making requests (Tannen 1981; Blum-Kulka 1983; García 1989; Wierzbicka 1991). But intracultural interaction is also prone to this sort of misattribution. In some eastern countries, for example, women are considered (over-)polite because their communicative style underscores deference, independence or the desire to avoid impositions (Ide 1989; Smith 1992; Kataoka 1995), while American women's preference 
for rapport-talk has been reported to sometimes earn many (derogative) adjectives from men, who seem to prefer report-talk (Tannen 1990).

An existing identity prejudice may even lead to interactive friction, conflict and communication breakdown when deviant practices are faced (Riley 2006). Between interlocutors from distinct city districts, areas, provinces, regions or states, for instance, personal questions may be regarded as intrusive, whereas inability to interrupt at the right moment during a conversation or excessively holding the floor may be considered to unveil discursive and pragmatic unskilfulness (Tannen 1987). Ascriptions of a lower level of pragmatic competence than individuals in fact possess may be dangerous, as they may reinforce a negative stereotype and contribute to disempowerment and discrimination (Thomas 1983; Tannen 1990; Beebe and Takahashi 1989; Kasanga 2001; Kasanga and Lwanga-Lumu 2007). Social epistemologists have identified and characterised various epistemic injustices committed towards individuals on the basis of alleged abilities and perceived performance. Unwarranted attributions of pragmatic incompetence may be regarded as such.

\section{4. (Mis)Attributions of Pragmatic (In)Competence and Epistemic Injustice}

Pragmatic failures may lead (prejudiced) individuals to erroneously conclude that the individuals committing them are less competent than expected or below average in pragmatic terms. Since this does not do justice to those individuals because it is a wrong construal of them -i.e. knowledge about them is inappropriately or unfairly constructed- those individuals become the victims of an epistemic injustice and their reputation as epistemic agents may 
ultimately be impaired (Fricker 1998, 2003, 2006, 2007). What must be unravelled is which epistemic injustice this wronging would amount to.

Initially, Fricker $(2003,2007)$ differentiated two epistemic injustices. The first one is testimonial injustice, or the unfairness that prejudiced people sustain when they think that the information that an individual dispenses is unreliable or false. As a transactional injustice resulting from interaction, it arises when an individual is assigned less credibility than deserved -i.e. a credibility deficit (Fricker 2003, 154; 2007, 21). Consequently, what she says is not automatically accepted as true, even if it really is, and the degree of belief is lowered. Here the issues are credibility and the wrong done on the grounds of the alleged falseness, scarce reliability or lack of support of a person's testimony (Fricker 2007).

Testimonial injustice is a form of negligence because an identity prejudice is allowed to influence judgements about the victim, so the perpetrator is culpable for failing to avoid its effects (Riggs 2012, 155). The victim suffers objectification because she is degraded from the category of informer or source of knowledge to that of mere object. ${ }^{7}$ This injustice may be avoided thanks to testimonial justice, the virtue facilitating awareness of prejudices and their impact on credibility judgements (Fricker 2007, 92). However, pursuit of this virtue may be hard: "[...] even when we suspect ourselves to be affected by prejudice and take measures to block its discriminatory effects, the virtue of testimonial justice is largely forced to operate in the dark: we do not know how much we are prejudiced against a speaker, and so do not know how much to correct for this bias" (Anderson 2012, 168; see also Sherman 2016). ${ }^{8}$

The second type is hermeneutical injustice, or the harm experienced when there is a "[...] collective hermeneutical lacunae [...]" which prevents an epistemic agent from "[...] rendering [her] experience communicatively intelligible" (Fricker 2006, 101). This injustice arises when a group lacks the conceptual repertoire facilitating expression of experiences. As a result, the 
victims have "[...] some significant area of their social experience obscured from collective understanding" (Fricker 2006, 99) and fail "[...] to make communicatively intelligible something which it is particularly in their interest to be able to render intelligible" (Fricker $2006,103)$. This injustice is structural because a society lacks the tools to allude to certain states of affairs. ${ }^{9}$ Here the issues are intelligibility and the wrong suffered because of inability to be understood as deserved or expected (Fricker 2006, 105-107; 2007, 151), which undermines the victims' self-trust -i.e. the reflexive attitude of confidence and optimism about their cognitive competence in some domain (Jones 2012, 241-242).

A hermeneutical injustice is a "[...] form of epistemic disempowerment [...]" because "[...] marginalised groups are at a cognitive disadvantage to the extent that there are often no concepts for describing the problems that they experience, while the powerful are advantaged by silence" (McCollum 2012, 190). This unfairness does not have a specific perpetrator or culprit, inasmuch as hearers are not to blame for not understanding what the victims seek to express (Fricker 2006, 102). Hermeneutical injustices are systematic, if they involve persistent negative biases, or incidental, if such biases are fleeting. The latter do not stem from "[...] any structural inequality of power but rather from a more one-off moment of powerlessness" (Fricker 2006, 100). ${ }^{10}$

To these two types of epistemic injustice Dotson (2012) further added contributory injustice, which originates when "[...] a person has the conceptual tools to comprehend her experience [...] and the linguistic tools to articulate it, but her attempts at communicating her ideas are thwarted by the fact that her audience willfully misunderstand her" (Dotson 2012, 32). This injustice is inflicted when interlocutors purposefully and decidedly refrain from understanding what a person says or, in other words, do not want to "[...] capture the ideas or experiences being expressed" (Dotson 2012, 32). Since what is said does not gain "[...] 
appropriate uptake" (Dotson 2012, 32), contributory injustices do have perpetrators: the individuals who intentionally refuse to understand it or render it unintelligible.

Finally, Anderson (2017a) has quite recently identified conceptual competence injustice, which is perpetrated when someone is not recognised as a knower or expert in some domain because of misuse or lack of specialised vocabulary, and is attributed lack of the corresponding concepts. It is "[...] a wrong done to a person specifically in their capacity as a knower of those claims that would traditionally be regarded as conceptual and linguistic truths" (Anderson 2017a, 1). This injustice is targeted at conceptualising abilities and lexical competence, since the victim is deemed to be unable to accurately discriminate elements of reality. As a result, her credibility decreases because she does not give the impression of possessing sound knowledge about the domain in question. Conceptual competence injustice is a structural injustice, a form of epistemic oppression (Dotson 2014), which occurs "[...] when false judgements of incompetence function as part of a broader, reliable pattern of marginalization that systematically undermine the epistemic agency of members of an oppressed social identity" (Anderson 2017b, 36). ${ }^{11}$

Communicators may appear to have comprehension troubles, perform unexpected or unpermitted actions from their interlocutors' perspective, or seek to accomplish them by resorting to pragmalinguistic strategies differing from those that the hegemonic group customarily employs. If their communicative skilfulness is put into question, they would be inflicted an epistemic injustice. The issue is whether this injustice may be subsumed by the epistemic injustices already identified.

Let us begin with testimonial injustice. A wronging ensuing from a comprehension mistake cannot be subsumed by this injustice because it concerns the ability to dispense information and the quality of information. Since neither informing nor information quality are at stake 
when pragmalinguistic or sociopragmatic failures are committed, an unfair appraisal of abilities resulting from them would not count as a case of testimonial injustice either. Rather, what is at stake is the capacity to select the best means to accomplish verbal actions and to perform them at the appropriate moment, in the right place and with the adequate interlocutor.

Let us now proceed to conceptual competence injustice. Underestimating speakers' abilities because of alleged pragmatic failures would not amount to this injustice when the vocabulary needed to perform (a) verbal action(s) is available. A speaker may possess the lexical resources to order a cup of coffee -e.g. 'cup', 'coffee'- but her problem may be unawareness of the structures conventionalised by a privileged group to accomplish that action -e.g. "May I have X?"- or ignorance of the norms regulating when, where and with whom that action is permissible. It is not conceptual knowledge that is the problem, but a wider-ranging knowledge: cultural knowledge, which encompasses knowledge about performance of verbal actions (Sperber 1996).

In contrast, undue attributions of a low level of competence after a comprehension mistake could be considered a conceptual competence injustice if the problem is a hearer's lexical and conceptual repertoires, and these hinder understanding. Although this injustice is perpetrated when speakers exhibit ignorance of vocabulary (Anderson 2017a), it would be reasonable to argue that it may also be targeted at hearers who experience comprehension troubles due to lexical and conceptual gaps. Imagine a professor using the relevance-theoretic term 'explicature', already introduced in class, during an explanation:

(13) Reference assignment, disambiguation, conceptual adjustment and recovery of elided material are necessary to construct an explicature. 
Failure to understand what is meant could make the professor conclude that a student is unfamiliar with relevance-theoretic vocabulary and doubt the actual degree of specificity of the student's vocabulary. However, regarding a wronging ensuing from a comprehension problem due to lexical gaps as a conceptual competence injustice would exclude other wrongings stemming from troubles at reference assignment, disambiguation, conceptual adjustment, recovery of unarticulated constituents, emotion-reading or derivation of intended implicit contents, which depend on inference and emotion-reading, and not simply on concepts and words.

Could pragmatic competence misappraisals resulting from alleged pragmatic failures or misunderstandings, then, be hermeneutical injustices? As long as hearers' intelligibility is not at stake when they make interpretative mistakes, attributions of deficient comprehension skills to them cannot. Inasmuch as there are not hermeneutical lacunae impeding intelligibility when speakers deploy unexpected or unusual strategies, or perform speech acts in inadequate circumstances, ascriptions of a low level of competence cannot either. Despite the unusualness and/or unexpectedness of the strategy employed, or the erroneousness of the circumstances, a request, for instance, evidences awareness of the requester's wants and of the person who can satisfy them, and conceptualising the action results in an attempt at it. The problem lies in the strategy and/or in the very decision to perform it, which cause the action and the manner whereby it is performed to be judged as inappropriate.

Even if the notion of hermeneutical injustice was loosened and only referred to an unfairness sustained when someone is not understood as expected or desired, misjudgements of pragmatic competence motivated by pragmatic failures could not be considered hermeneutical injustices. Performed verbal actions are understood, but they achieve an unexpected perlocutionary effect: they are evaluated as inadequate because of diverging 
patterns or abidance by differing interactive norms. Moreover, such misjudgements cannot be hermeneutical injustices because (i) there are culprits -hearers-and proper hermeneutical injustices do not have perpetrators, and (ii) the misjudgement is a consequence of infelicitous performance, which suggests a pragmatic competence deficit.

What about classifying pragmatic competence underestimations as cases of contributory injustice? When they stem from comprehension problems, they cannot feature as such injustice because they are triggered by hearers' inability to understand their interlocutors correctly, not by speakers' failure to gain appropriate uptake. Nor are they contributory injustices when they originate in alleged sociopragmatic failures, as verbal actions are understood, but their performance is deemed unfortunate. If they are motivated by seeming pragmalinguistic failures, they could only count as contributory injustices if the audience refrained from making any effort to understand the means whereby actions are performed, which appear unusual or odd to them, and questioned the speakers' competence (see below). In other words, for a pragmalinguistic failure to result in a contributory injustice, the audience must be unwilling to concede that a speaker might be familiar with and customarily resort to strategies that (considerably) differ from those they normally use, refrain from making sense out of what they hear and wonder what the speaker might have meant.

\section{An Injustice Concerning Pragmatic Skills}

Clearly, the unfairness a(n) (marginalised) epistemic agent may sustain because of allegedly inadequate pragmatic performance cannot be described as a testimonial, conceptual competence, hermeneutical or contributory injustice. Another label is needed in order to 
identify a wrong done on the grounds of seeming comprehension problems or contravening a (privileged) group's speech-act realisation conventions, norms and expectations. In an analogous manner to Anderson's (2017a) 'conceptual competence injustice', that label could be pragmatic competence injustice, which would capture an unfortunate misappraisal of pragmatic skills.

Pragmatic competence injustice may be defined as the injustice perpetrated against a communicator -speaker or hearer- whenever pragmatic performance -production or comprehension- is deemed, to a greater or lesser extent, deficient, unusual or deviant from what most of the members of $a(n)$ (empowered) community of practice would regard as adequate, acceptable, expectable or desirable to achieve the expected outcome of communication -smooth mutual understanding- and the communicator's pragmatic knowledge is questioned or misrepresented. This type of epistemic injustice only affects a component of communicative competence: namely, pragmatic competence. It is inflicted whenever perception of pragmatic performance, or actualisation of the abstract knowledge and capacities, leads the members of the (privileged) community of practice, on the basis of assumed standards or recurrent habits, to a negative assessment of an (unprivileged) individual. That assessment must cause the judgers to question the victim's pragmatic skilfulness and, ultimately, doubt their knowledge.

Pragmatic competence injustice may be thought to be merely a form of competence injustice (Anderson 2018, 31) because it involves skills for behaving and processing input correctly, so it may be considered to just amount to a misappraisal of those skills. However, pragmatic competence injustice is an epistemic injustice because it certainly involves knowledge about specific areas of language and communication: knowledge about the inventory of strategies to achieve specific goals - pragmalinguistic knowledge (Leech 1983)- 
knowledge of the norms governing behaviour -sociopragmatic knowledge (Leech 1983)- and knowledge about how to manipulate linguistic input in order to arrive at the speaker's meaning. A part of such knowledge is acquired intuitively, without full awareness of its acquisition, as a consequence of growth and exposure to the behaviour of the other members of a community of practice, so it consists of intuitive beliefs (Sperber 1997), or "[...] beliefs held without awareness of reasons to hold them" (Mercier and Sperber 2011, 58). Another part is acquired reflectively, as a result of explicit instruction - remember when parents tell children what to say or how not to say something in a particular situation- so it is made up of reflective beliefs (Sperber 1997), which are "[...] held with awareness of one's reasons to hold them" (Mercier and Sperber 2011, 58). Inflicting a pragmatic competence injustice involves considering that its victim lacks or does not have mastery of the pragmalinguistic knowledge enabling selection of the resources that are suitable for achieving a communicative goal, is unaware of the sociopragmatic norms endorsed by a community of practice or, in the case of misunderstanding, does not know how to process input. Therefore, the sustainers of this injustice may be regarded to have gaps in their set of beliefs connected with the relevant area. Misjudgements of comprehension abilities might even be argued to amount to competence injustices, and not to be epistemic in nature, because what are involved are competencies that are enacted almost automatically, incredibly quickly and subconsciously by a series of cognitive modules. However, enactment of those competences also depends on knowledge. Consider a task like reference assignment: for a hearer to correctly assign reference to, for instance, deictics -'here', 'there', 'now', 'then'- he must know that each of them call for a specific temporal or spatial referent that is (not) in his proximity or the speaker's proximity as a result of the procedural meaning or computational instruction that they encode (Blakemore 1987; Wilson and Sperber 1993). Additionally, think of a task like 
attribution of mental states and emotions to interlocutors: hearers must be capable of inferring states like (un)certainty or (dis)belief from verbal mood, evidential adverbials -e.g. 'obviously', 'clearly', 'evidently' - or hearsay adverbials -e.g. 'reportedly', 'allegedly', etc.- as well as of 'reading', so to say, emotions correctly from facial expressions, gestures, intonation, interjections or attitudinal adverbials -'happily', 'sadly', etc. These (para)linguistic elements also encode processing instructions steering the mental operations involved in comprehension (Ifantidou 1992, 1993, 2001; Wilson and Sperber 1993; Wilson and Wharton 2006; Wharton 2009) and hearers must also know what the expected output of their instructions is or, to put it differently, they must know what those instructions involve. Although procedures are subconscious and intuitive, and they result from exposure to language use, they involve knowledge, as does familiarity with a repertoire of expressions adequate to specific circumstances or acquaintance with behavioural norms. Accordingly, pragmatic competence injustice is an epistemic injustice because it impacts knowledge indispensable for performance.

Pragmatic competence injustice is also, to some extent, a structural injustice. At least, when it stems from pragmalinguistic or sociopragmatic failures, it involves the repertoire of linguistic means available to a community of practice that is considered appropriate for achieving specific communicative goals, as well as the set of tacitly or explicitly established interactive norms regulating behaviour in that community of practice and determining expectations about other people's behaviour. Although those norms may be restrictive and exclusive, as they may not encompass, match or be similar to the standards followed by the members of other communities of practice, it is against them that the behaviour of not only the members of the community of practice in question is assessed, but also that of the members of other communities. In so doing, the validity and applicability of those norms are 
(over-)generalized, as they are extended to the behaviour of the members of other communities, even if they lack the specifications or precepts, so to say, considered correct in their respective community. In other words, pragmatic competence injustice is a structural injustice because social groups may lack the set of tools enabling correct understanding and fair appraisal of other individuals' behaviour: there would be gaps in the inventory of pragmalinguistic resources suitable for performing speech acts or in the set of sociopragmatic norms governing and constraining behaviour.

The victims of testimonial and contributory injustices are speakers who seek to communicate. Likewise, the victims of hermeneutical injustices are also speakers, even if they cannot articulate their experience and make it intelligible. The target of a conceptual competence injustice, however, is a speaker or a hearer who evidences deficits in her/his conceptual repertoire, which prevents her/him not only from categorising and alluding to reality, but also from understanding what other communicators may refer to. Similarly, pragmatic competence injustices may be sustained against speakers or hearers. Speakers receive this injustice when, on the grounds of assumed regularities or common habits, they are unduly considered not to have selected the appropriate verbal means to perform speech acts or when they are unwarrantedly judged not to have correctly calibrated contextual factors governing and somehow constraining their accomplishment. When a pragmatic competence injustice is inflicted, a speaker is unfairly deemed not to master the pragmalinguistics of a language -i.e. the conventionalised associations between semanticosyntactic structures and illocutionary force- or its sociopragmatics -i.e. the norms internalised by a community of practice determining when, where, why or with whom certain behaviours are permitted. 
On the other hand, hearers suffer a pragmatic competence injustice when they are thought to have misunderstood their interlocutors or what has been said because of an alleged interpretative mistake. A hearer sustains this injustice not exclusively if he is believed not to have reached the locutionary level of an utterance or stretch of discourse -i.e. its semanticsbecause of a supposedly wrong output of decoding and the inferential tasks involved in reference assignment, disambiguation, conceptual adjustment or recovery of elided material. Probably more importantly, a hearer receives this injustice if he is felt not to have grasped the ilocutionary force -i.e. the speaker's actual intentions- or not to have inferred some expected or necessary implicature because of alleged lack of knowledge, erroneous inference or misattribution of intentions and/or emotions to the speaker.

Regardless of whether the victim is a speaker or a hearer, a pragmatic competence injustice has easily identifiable culprits, but these obviously vary. When a speaker receives it, the perpetrator is a hearer, who interprets what she has said or done by means of words, and negatively evaluates it and the speaker. In contrast, when it is a hearer that receives it, the perpetrator is a speaker who feels that he has not correctly understood her words or grasped her intentions. In both cases, nevertheless, performance is negatively assessed and gives the impression that the performer may be incompetent in pragmatic terms. The perpetrator only needs to think that performance is inadequate at a particular time, in a specific place, with a certain (type of) interlocutor and/or in some area, and conclude that the victim's competence is below (an) alleged standard(s).

Skilfulness in a particular area may exceed skilfulness in (an)other(s). For instance, in terms of production, a speaker may be tactful or respectful when formulating invitations or paying compliments, but not when requesting or apologising; in terms of comprehension, a hearer may easily and immediately capture double senses or disambiguate sentences, but have 
difficulty in arriving at implicatures or in reading emotions. Accordingly, judging a language user as incompetent, or less competent than average, in an area of pragmatics -production or comprehension- or just in specific sub-areas -e.g. speech-act realisation or any of the tasks in mutual parallel adjustment- should not necessarily imply that they are completely denied pragmatic competence, not to say communicative competence. Rather, the language user could be less skilled or completely unskilled only as regards the area or sub-area of pragmatics in question, and they may be perceived in this way only by another user or more members of a community of practice. Furthermore, performance may be hindered by a variety of psychological, physiological and personal factors (Mustajoki 2012; Padilla Cruz 2017a); unawareness of any of them may in part motivate unfair ascriptions of pragmatic competence levels (Padilla Cruz 2017b, 2017c). The problem in pragmatic competence injustice is that performance and competence are evaluated from an individual or community of practice's perspective, and prejudice influences such an assessment.

Sustainers of testimonial injustices are not considered reliable or trustworthy informers, are objectified and the information that they impart is questioned or not believed at all. The targets of contributory injustices find themselves hampered in their effort(s) to be understood. In turn, victims of hermeneutical injustices are denied epistemic trustworthiness and are degraded as knowers. They may be pre-emptively silenced if they are banned from communicative exchanges, or epistemically objectified if they are allowed participation in communicative exchanges but are not treated as informants (Fricker 2007, 130-133) or as inquirers who could participate at more sophisticated activities requiring higher levels of abstraction and epistemic authority (Medina 2012, 203-204). Finally, sufferers of conceptual competence injustices get their (domain-specific) conceptual repertoires and lexical skills called into question, and are conceived of as less competent as regards specialised vocabulary. 
Ignorance of (specialised) lexicon involves lack of veridicality and may ultimately lead to testimonial quieting if an audience refuses to pay attention to someone or accept what they say about a domain (Dotson 2011). Although conceptualising and neatly differentiating elements or nuances of reality is undoubtedly a pivotal component of communicative competence, the victim of a conceptual competence injustice would not be denied communicative competence as a whole, nor should they be denied lexical competence in absolute terms, as they would certainly store concepts for elements of other domains of reality. Instead, , in a similar way to hermeneutical injustices, their knowledge of the domain in question would not be acknowledged or they would alternatively get the width, accuracy and soundness of that knowledge challenged. Hence, a conceptual competence injustice could be said to deprive the victim of what could be labelled conceptual accuracy, which may be portrayed as the capacity to forge the adequate mental objects to capture domain-specific elements of reality. This would be a prerequisite for lexical efficiency or lexical reliability, or the ability to use vocabulary appropriately. Both conceptual accuracy and lexical reliability/efficiency should feature as requirements for lexical competence and, obviously, for communicative competence.

If these epistemic injustices have the said consequences, what are the consequences of pragmatic competence injustice? Obviously, the information imparted is not questioned, attempts to communicate are not thwarted, the victim is not denied epistemic trustworthiness, nor are they denied conceptual accuracy or lexical reliability/efficiency. The effect of pragmatic competence injustice would be a deprival of what may be called pragmatic efficiency or pragmatic reliability (Padilla Cruz 2014), which may be described as a twofold characteristic. On the one hand, it is the ability to make manifest one's informative intention in a clear and effortless manner -the capacity to get across the intended messages 
economically in terms of cognitive effort (Sperber and Wilson 1986/1995)- and to adapt what is said to the sociocultural context where communication takes place with a view to achieving the desired goals. ${ }^{12}$ On the other hand, pragmatic efficiency/reliability is the ability to process language correctly and to arrive at speaker's meaning. To put it differently, pragmatic efficiency/reliability amounts to effectively actualising the abstract knowledge supporting pragmatic competence, which is essential to attain communicative efficiency and ensure the success of communication.

Pragmatic competence injustice may also give rise to contributory injustice (Dotson 2012) or strengthen an existing injustice of this type. Just as some black women's expressions of anger in conversations about racism were regarded as inappropriate because they contravened white women's norms pertaining to the expression of certain feelings in that context, so their subsequent critiques of white feminism were ignored (Lorde 1981), a person who (repeatedly) commits pragmalinguistic or sociopragmatic failures when attempting to accomplish specific actions may fail to achieve the expected outcome and their attempts at that action may be subsequently ignored. Consider the case of children who do not add 'please' to their requests and whose parents refrain from complying with their requests and let them know that they will not give them what they want unless they use the "magic word". Similarly, speech acts accomplished by seemingly odd formulae or in apparently erroneous circumstances may go unheeded because the performer has previously been evaluated in a variety of (negative) ways. This might be the case of a complainer who has already voiced her dissatisfaction at some event without any mitigation or without explaining the reasons for her complaint, but charging the complainee with the responsibility for her dissatisfaction or unhappiness. The complainer's subsequent complaints could be absolutely ignored because of the vehemence and directness previously perceived in her. 
Supposed failure to make manifest informative intentions in the least effort-demanding manner -misstatement- to generate utterances that match the sociocultural context pragmatic failure- or to correctly understand-misunderstanding-may result in a questioning of pragmatic competence. Pragmatic competence injustice is a competence injustice with an epistemic nature because an interlocutor's communicative efficiency is doubted, so the knowledge and skills upon which this depends are eventually questioned. Hence, the interlocutor may eventually be degraded as a (competent) language user and ultimately as a knower. If such a degradation is occasional, momentary, a one-off thing, the injustice would be incidental. However, if alleged incompetence is repeatedly detected, such a degradation may be a more enduring or permanent phenomenon, so the injustice could become systematic. In any case, pragmatic competence injustice also undermines the interlocutor's self-trust and makes them unconfident or uncertain about the effectiveness and success of their (pragmatic) performance (Jones 2012, 244). Feeling or realising that their linguistic choices are misunderstood, that their decisions to behave in a particular manner in a situation does not get the appropriate uptake or that other interlocutors doubt their processing abilities, the target of this injustice may (constantly) wonder what causes them to be misunderstood or be perceived as an inept hearer, and be subsequently inhibited from doing certain things with words in specific contexts or appearing in a particular manner in front of other individuals. The perpetrator of this injustice, in turn, may become arrogant, dogmatic and narrow-minded in pragmatic terms, as they are unwilling to accept the existence of other valid linguistic means to achieve specific ends, that other individuals may abide by differing interactive norms or that comprehension may be affected by a variety of psychological and physiological factors, so it is not always a smooth and error-free process (Medina 2011, 17). Ultimately, they may even become normative, prescriptive and exclusive. 


\section{On the Origin of Pragmatic Competence Injustice}

Performance may be affected by a variety of states and problems. In addition to phonological, morphological, lexical, syntactic or pragmatic problems -which sometimes reveal certain deficits- interlocutors may lack cultural assumptions or metarepresentations (Sperber 1996) concerning interaction. These determine, for instance, (non-)permitted or (dis)preferred actions in specific circumstances, (in)adequate conversational topics, (dis)preferred linguistic structures for some speech acts, etc. Alternatively, the content of those metarepresentations may vary across interlocutors, above all, if they belong to different communities of practice.

Ostensive stimuli generate expectations of optimal relevance, i.e. hopes that the effort that will be invested in processing them will be offset by cognitive gains: strengthening of previous information, contradiction (and eventual elimination) of old information or derivation of new information, i.e. contextual implications. These arise from contextualisation, an inferential process whereby the informational load of stimuli is related to already stored information, perceptible information or assumptions constructed on the fly (Sperber and Wilson 1986/1995; Wilson and Sperber 2002, 2004).

During contextualisation, a domain-specific mechanism that is part of the general inferential or pragmatic mechanism, the social categorisation system (Barkow et al. 1992; Escandell Vidal 2004), subconsciously analyses and evaluates performance in accordance with assumptions regarding interaction. These make up some kind of database and act as implicated premises in the computations that the system makes (Sperber and Wilson 1986/1995). If its database contains no information connected with a particular behaviour, 
the behaviour becomes irrelevant because its processing does not yield any cognitive gain. Since the system relies exclusively on the information in its database, it may also derive unwanted or alternative implicated conclusions (Escandell Vidal 1998; Yus Ramos 1999a, 1999b), which may cause a behaviour to be accidentally interpreted in a manner that differs from how the individual producing it might have intended or expected it to be interpreted (Wilson 1999) -e.g. as inadequate, puzzling or weird.

Performance makes manifest assumptions about language users and their behaviours. Prejudice may also favour immediate access to (negative) assumptions regarding language users, behaviours and performance. Those assumptions are thus brought to the fore and become highly salient (Giora 1997), so they are amenable to being promptly and effortlessly supplied as implicated premises in the computations of the system (Padilla Cruz 2017c). From them, the system may straightforwardly and easily draw implicated conclusions about the behaviour in question and its producer. Since such conclusions are not in the interest of the producer, they give rise to detrimental or prejudicial interpretations, or counterinterpretations (Medina 2012, 210).

Derivation of such interpretations may be explained by a number of factors (Padilla Cruz 2017a):

a) Deployment of a simple processing strategy (Padilla Cruz 2012). Human cognition is relevance-driven, so input processing follows the path of least effort and maximum benefit, and stops upon reaching an interpretation that satisfies expectations of relevance (Wilson 1999; Wilson and Sperber 2002, 2004). This strategy is naïve optimism (Sperber 1994) and induces individuals to presuppose that the social categorisation system possesses the information that is necessary and suitable for its 
tasks. Consequently, interpretations that are constructed upon that information and achieve optimal relevance are automatically assigned plausibility.

b) Confirmation bias, or the tendency to tenaciously adhere to conclusions that seem sufficiently supported by available information (Friedrich 1993; Nickerson 1998; Kunda 1999). This tendency makes individuals retain conclusions effortlessly and straightforwardly drawn, and prevent them from wondering whether behaviour could be evaluated differently (Klayman 1995).

c) Weak vigilance. A suite of mental mechanisms scrutinise, on the one hand, the reliability of information and its sources, and, on the other hand, the correctness of the tasks that the mind performs. These mechanisms trigger an attitude of epistemic vigilance, or the necessary scepticism for avoiding blindly believing any information or anybody and being, therefore, deceived (Mascaro and Sperber 2009; Sperber et al. 2010). Additionally, they also trigger an attitude of hermeneutical vigilance that facilitates introspection and reconstruction of the steps likely to have been taken in an inferential process, the information used and the plausibility of the conclusions. As a consequence, mistakes or infelicities may be detected, and more viable alternatives may be sought (Padilla Cruz 2014, 2016). Like other mental mechanisms, vigilance mechanisms may be activated to a higher or lesser degree; if they are weakly activated, they may fail to fulfil their tasks (Michaelian 2013; Sperber 2013).

(Prejudiced dominant) Individuals do not question the adequateness of the premises upon which assessment of (unprivileged) individuals' performance relies or the fairness of their assessments. Nor do they even wonder whether there might be alternative ones, but tenaciously hold on to theirs. Unaware that "[...] communicative contexts are always polyphonic, and the plurality of experiential and hermeneutical perspectives in any given 
context is such that we can always find voices that depart from the available communicative practices and dynamics" (Medina 2012, 209), and that other people's performance may be affected by various factors, (prejudiced) individuals blindly trust in the suitability of the information available to them for judging behaviour and in their judgements. They do not behave as cautiously optimistic individuals, who critically interrogate themselves about the accuracy of that information or the fairness of their evaluations (Sperber 1994). Therefore, they cannot seek the epistemic friction necessary for searching for alternative information that yields a distinct, non-negative evaluation (Medina 2011, 29).

Failure to exercise hermeneutical vigilance of information regarding behaviour and of evaluations (Padilla Cruz 2014, 2016) prevents (biased hegemonic) individuals from noticing the limitations of their "[...] interpretative resources $[. .$.$] " and the narrowness of their "[...]$ interpretative horizons" (Medina 2012, 216). This places them in a state of active ignorance wherein they recalcitrantly resist new or diverging manners of expressing meaning, or unexpected, seemingly odd behaviours (Medina 2011, 26; 2012, 213), and cannot admit that "[...] within distinctive publics with their peculiar resources, there will be expressive differences, deviations, and idiosyncrasies" (Medina 2012, 211), or that certain factors may affect other individuals and impede their performance to differing extents. In such a state, they cannot be hermeneutically open to other expressive choices, the existence of other interactive norms determining other people's behaviours or the influence of diverse factors on performance. Rather, they are meta-blind, unaware of the "[...] cognitive and affective limitations of [their] perspective" (Medina 2011, 29) on language use and communicative performance. This prevents them from looking at (stigmatised) individuals' styles and habits of speaking and interacting from another viewpoint (Medina 2011, 29), which prevents them from being empathetic interlocutors who manage to see linguistic structures, formulae, 
patterns, decisions pertaining linguistic actions, etc., from the speaker's perspective and hear, analyse, assess and appraise them as the speaker would expect and desire (Medina 2011, 31) or, at least, with some degree of benevolence.

Meta-blindness, active ignorance and hermeneutical closedness to the reasons underlying an individual's seemingly strange behaviour may be found in a situation that one university professor experienced. He had asked his foreign learners of Spanish as a second language to prepare an oral presentation about their house and neighbourhood. The day when the students had to do their presentations, the professor asked a Japanese student to do hers, but she refused. The professor then insisted a few times that all students had to do their presentation, but she kept of refusing. He even checked whether the student was afraid of speaking in front of her classmates and offered her to do the presentation alone, if that was the case; he also tried to calm her down in case she was nervous or anxious that her Spanish was not good enough. However, he only got a reiterated "no, no, no, please", which led him to think that the student had not prepared her assignment and was lying to him, so he gave her a fail grade. Having told students to prepare a task and to present it in class, the professor expected them to be willing to do it as a way of getting feedback on their Spanish and their speaking skills, an expectation that originated in beliefs about his role, duties, good teaching practices, students' needs and interests, etc.

Days after that class, while discussing the grades that students had got for their midterm, the Japanese student explained that she had not wanted to do her presentation for two reasons. Firstly, she lived in a well-off neighbourhood and her family owned a large and sumptuous house that was very different from her classmates' residences, so she did not want to talk about that in order to prevent their classmates from thinking that she was showing off. Secondly, she considered having to talk about her house a violation of her privacy, which was 
something that she highly valued. Unaware of the importance of modesty and privacy to the student and relying on his own beliefs, the teacher failed to realise that the student's reluctance to do the task might have been motivated by abidance by other interactive norms or idiosyncratic beliefs. Failure to exercise vigilance of the suitability of his beliefs to that situation rendered the professor hermeneutically closed to the norms and beliefs about modesty and privacy that the Japanese student endorsed, and made him analyse her behaviour as an indication of deception.

From the student's perspective, however, the professor's failure to make an effort to look at her from another angle and to be empathetic led her to regard his behaviour as excessively strict, stubborn and over-demanding, and to regard him as incompetent. In the same way a person is ascribed testimonial incompetence because of failure to demonstrate understanding of the content of testimony and to detect what impedes their understanding (Dotson 2011, 245-246), to the Japanese student the professor's incompetence was due to his demonstration of misunderstanding her behaviour, impossibility to figure out the reasons prompting it and inability to discover what hindered his understanding. Confirmation bias and weak vigilance of the suitability of his own beliefs about interaction for making sense out of the Japanese student's behaviour made the professor almost blindly adhere to the conclusions drawn from those beliefs. He could not detect any gap in them, so he was insensitive to his lacking knowledge about the norms the student might abide by. ${ }^{13}$

\section{Conclusion}


Ignorance of or unfamiliarity with the linguistic structures conventionalised in non-dominant communities of practice as adequate means of achieving specific communicative goals, insensibility to differing communicative habits and interactive norms, and/or unawareness of factors likely to hinder comprehension may induce negatively biased members of hegemonic social groups to wrong unprivileged language users in their capacities as communicative agents. As long as that wronging eventually involves questioning the knowledge and skills enabling their communicative performance, it may be considered an epistemic injustice, even if what is at issue is not the ability to dispense accurate, complete and trustworthy information; the conceptual repertoire and vocabulary necessary for properly talking about certain domains of experience, or intelligibility. Since such wronging has distinguishable features and particular effects that differentiate it from other epistemic injustices already identified in the field of social epistemology, it may be referred to through the label proposed in this paper: pragmatic competence injustice. This new label highlights that the unfairness that may be inflicted upon marginalised individuals is due to their actualisation of just a part of the abstract knowledge and skills making up the broader capacity to use a language, and the sort of things they do when engaging in social interaction: accomplishing verbal actions and processing what other people say.

Having pragmatic knowledge and skills misjudged does not imply being completely disavowed communicative competence, for the other components of this overarching capacity -i.e. phonology, morphology, lexicon, syntax- may be perceived to be intact and to be acceptably or moderately well deployed. Rather, what is questioned from the angle of the dominant milieu is mastery of the 'know-how' of the language, which is enough to downgrade someone as an effective language user and, therefore, as a knower of a language and its associated practices and constraints. This downgrading may be as pernicious as other 
epistemic injustices because of its dramatic consequences upon the individual whose pragmatic competence is misjudged.

Conversational styles, as evidenced by pragmalinguistic and sociopragmatic choices, may lead to the exclusion from certain jobs, for instance, in the service, tourism or media industries. Think of candidates for positions as waiters or tourist informers who are seen as bold, direct or impolite because of how they address their interlocutor(s) at a job interview, or consider the case of a journalism graduate who is not hired because she is perceived as dull or boring, unenthusiastic or lacking engagement while reading a piece of news during another job interview. Likewise, erroneous decisions as to what to do at a particular moment, what to say or how to say it may hinder success in educational systems or even ruin a whole career. This is what often happens, for instance, to some students, politicians and civil servants. Even if students know the theory or have the requisite skills in a discipline, they may receive lower grades than they expect or deserve because of their speech and/or behaviour when proving their knowledge, causing instructors to consider that they lack social skills -an asset that educational systems are quite frequently supposed to foster. In the case of politicians and civil servants' careers, consider the recent case of a politician whose resignation many citizens demanded because of some comments made in public -a sociopragmatic decision, as long as it pertains to what to talk about, when and in front of whom- to the effect that pensioners do have economic resources -a thorny issue at that time in his country- if they own properties that they can sell. Finally, abiding by differing interactive rules, failing to figure out those followed by others or making unfortunate choices may also prevent participation in social networks. Nowadays, for instance, many people unfollow, or even unfriend, someone on a virtual social network because of the sort of contents they post -again, a sociopragmatic decision- or how they say things about a particular issue -a pragmalinguistic decision. Think 
of those 'virtual friends' who constantly attack or censure certain political ideas or decisions or whose posts merely amount to fierce critiques of specific politicians or activists.

Further research could examine other areas where the impact of pragmatic competence injustice may have dramatic consequences: marketing, interaction with police officers, judges, prosecutors, social workers or planning boards, to name just a few. It would also be illuminating to elucidate additional factors causing people inflict pragmatic competence injustices. For instance, ego boundaries, or the openness and receptiveness to unknown situations and experiences (Hartmann 1991; Ehrman 1999), and tolerance of ambiguity, or the capacity to deal with unusual, and maybe contradictory, experiences, and to integrate them into one's cognitive structures (Furnham and Ribchester 1995), are crucial personal characteristics underlying the perpetration of pragmatic competence injustices. Probably, thick ego boundaries and low tolerance of ambiguity are responsible for many of these injustices. Finally, it would be interesting to analyse how pragmatic competence injustice reinforces an already existing unfavourable stereotype, and/or combine with (an)other injustice(s) and fosters or furthers disempowerment and discrimination. Indeed, questioning the ability to efficiently use and to understand language may give additional reasons for doubting capacities in other epistemic domains and skilfulness to engage in distinct epistemic practices.

\section{Notes}


[1] The third person singular feminine personal pronoun will be used throughout this paper to refer to the speaker, while the masculine counterpart will be used to refer to the hearer.

[2] A community of practice is a sociocultural group whose members share a repertoire of forms enabling successful participation in a variety of activities (Wenger 1998, 76).

[3] These acronyms stand for noun phrase (NP), adjective (ADJ), pronoun (PRO) and verb (V).

[4] These are indirect realisations because their semantic content (locutionary level) amounts to a question about the hearer's physical abilities (4) or a request for permission (5). In a situation where the speaker wants or needs something, and the hearer is able and willing to provide her with it, these structures are automatically assigned a requestive interpretation because the hearer captures their requestive illocutionary force (Austin 1962; Searle 1969, 1975).

[5] Upgraders reinforce the illocutionary force of an utterance and downtoners attenuate it.

[6] The grave accent mark indicates falling intonation.

[7] Pohlhaus (2014) considers that victims of testimonial injustices are treated as derivatised subjects because, despite their ability to maintain epistemic practices that make sense of their experiences as conceptualised by dominant groups, they are not given epistemic support, so what they try to express is actively prohibited or left unrecognised.

[8] Munroe (2016) differentiates two subtypes of testimonial injustice:

a) Descriptive credibility deficit, or lowering of credibility because of a negative identity prejudice.

b) Prescriptive credibility deficit, or lowering of credibility because a prescriptive stereotype establishing what ought to be done in a context is thought to be flouted. 
[9] McCollum (2012) proposes a modification of hermeneutical injustice that captures the conceptual lacunae in social institutions which create vocabularies that solely enable their members to shape the claims they may need to make.

[10] Romdenh-Romluc (2016) clarifies that victims of hermeneutical injustices may sometimes understand their experience but fail to successfully communicate it not because of general lack of conceptual tools, but because only a dominant group lack those tools and its members reject a description through the tools employed by marginalised individuals.

[11] For comments on conceptual competence injustice, see Padilla Cruz (2017b, 2017c), Anderson (2017b) and Podosky and Tuckwell (2017).

[12] A speaker's informative intention is the set of assumptions that she intends to make manifest or, in other words, the thoughts that she intends the hearer to entertain (Sperber and Wilson 1995, 58).

[13] What the student thought about the professor in this situation can also help illuminate cases of testimonial incompetence (Dotson 2011): individuals may appear as testimonially incompetent as a result of not exercising active vigilance of the sort and amount of knowledge that they possess about a particular domain that is (being) talked about, thinking that they possess the requisite knowledge to understand what is (being) talked about and being close to the possibility that they could miss something.

\section{References}

Anderson, Derek E. 2017a. "Conceptual Competence Injustice." Social Epistemology: A Journal of Knowledge, Culture and Policy $31 \quad$ (2): 210-223. https://doi.org/10.1080/02691728.2016.1241320 
Anderson, Derek E. 2017b. "Relevance Theory and Conceptual Competence Injustice." Social Epistemology Review and Reply Collective 6 (7): 34-39. http://wp.me/p1Bfg0-3Ec

Anderson, Derek E. 2018. "Yes, There Is Such a Thing as Conceptual Competence Injustice." Social Epistemology Review and Reply Collective 7 (1): 26-35. https://wp.me/p1Bfg0-3SL

Anderson, Elizabeth. 2012. "Epistemic Justice as a Virtue of Social Institutions." Social Epistemology: A Journal of Knowledge, Culture and Policy 26 (2): 163-173. https://doi.org/10.1080/02691728.2011.652211

Ardissono, Liliana, Guido Boella, and Rossana Damiano. 1998. "A Plan-based Model of Misunderstandings in Cooperative Dialogue." International Journal of Human-Computer Studies 48: 649-679. doi: 10.1006/ijhc.1997.0185

Austin, John L. 1962. How to Do Things with Words. Oxford: Oxford University Press.

Bachman, Lyle F. 1990. Fundamental Considerations in Language Testing. Oxford: Oxford University Press.

Banks, Stephen P., Gao Ge, and Joyce Baker. 1991. "Intercultural Encounters and Miscommunication." In "Miscommunication" and Problematic Talk, edited by Nikolas Coupland, Howard Giles and John M. Weimann, 103-120. London: Sage.

Barkow, Jerome H., Leda Cosmides, and John Tooby, eds. 1992. The Adapted Mind. Oxford: Oxford University Press.

Bazzanella, Carla, and Rossana Damiano. 1999. "The Interactional Handling of Misunderstanding in Everyday Conversations." Journal of Pragmatics 31: 817-836. doi: $10.1016 / \mathrm{S} 0378-2166(98) 00058-7$

Beebe, Leslie M., and Tomoko Takahashi. 1989. "Do You Have the Bag? Social Status and Patterned Variation in Second Language Acquisition." In Variation in Second Language Acquisition (Vol. 1: Discourse and pragmatics), edited by Susan Gass, Carolyn Madden, Dennis 
Preston and Larry Selinker, 103-125. Clevedon: Multilingual Matters.

Blakemore, Diane. 1987. Semantic Constraints on Relevance. Oxford: Basil Blackwell.

Blum-Kulka, Shoshana. 1983. "Interpreting and Performing Speech Acts in a Second Language:

A Cross-cultural Study of Hebrew and English." In Sociolinguistic and Language Acquisition, edited by Nessa Wolfson and Elliot Judd, 36-55. Rowley: Newbury House.

Brown, Gillian. 1995. Speakers, Listeners and Communication. Explorations in Discourse Analysis. Cambridge: Cambridge University Press.

Canale, Michael. 1983. "From Communicative Competence to Communicative Language Pedagogy." In Language and Communication, edited by Jack C. Richards and Richard W. Schmidt, 2-28. London: Longman.

Carston, Robyn. 2002. Thoughts and Utterances. The Pragmatics of Explicit Communication. Oxford: Blackwell.

Celce-Murcia, Marianne, Zoltán Dörnyei, and Sarah Thurrell. 1995. "Communicative Competence: A Pedagogically Motivated Model with Content Modifications." Issues in Applied Linguistics 5: 5-35. https://escholarship.org/uc/item/2928w4zj

Chomsky, Noam. 1965. Aspects of the Theory of Syntax. Boston: MIT Press.

Clark, Herbert H., and Edward R. Schaefer. 1989. "Contributing to Discourse." Cognitive Science 13: 259-294. https://doi.org/10.1016/0364-0213(89)90008-6

Codó Olsina, Eva. 2002. “Managing Understanding in Intercultural Talk: An Empirical Approach to Miscommunication." Atlantis 24 (2): 37-57.

Dascal, Marcelo. 1999. "Introduction: Some Questions about Misunderstanding." Journal of Pragmatics 31 (6): 753-762. https://doi.org/10.1016/S0378-2166(98)00059-9 de Saussure, Ferdinand. 1916. Cours de Linguistique Générale. Paris: Payot. 
Dotson, Kristie. 2011. "Tracking Epistemic Violence, Tracking Practices of Silencing." Hypatia 26 (2): 236-257. doi: 10.1111/j.1527-2001.2011.01177.x

Dotson, Kristie. 2012. “A Cautionary Tale: On Limiting Epistemic Oppression." Frontiers: A Journal of Women Studies 33 (1): 24-47. doi: 10.5250/fronjwomestud.33.1.0024

Dotson, Kristie. 2014. “Conceptualizing Epistemic Oppression.” Social Epistemology: A Journal of Knowledge, Culture and Policy 28 (2): 115-138. https://doi.org/10.1080/02691728.2013.782585

Dua, Hans R. 1990. "The Phenomenology of Miscommunication." In Beyond Goffman, edited by Stephen H. Riggins, 113-139. Berlin: Mouton de Gruyter.

Eelen, Gino. 2001. A Critique of Politeness Theories. Manchester: St. Jerome.

Ehrman, Madeline. 1999. "Ego Boundaries and Tolerance of Ambiguity in Second Language Learning." In Affect in Language Learning, edited by Jane Arnold, 68-86. Cambridge: Cambridge University Press.

Escandell Vidal, M. Victoria. 1998. "Politeness: A Relevant Issue for Relevance Theory." Revista Alicantina de Estudios Ingleses 11: 45-57.

Escandell Vidal, M. Victoria. 2004. “Norms and Principles. Putting Social and Cognitive Pragmatics Together." In Current Trends in the Pragmatics of Spanish, edited by Rosina Márquez-Reiter and María E. Placencia, 347-371. Amsterdam: John Benjamins.

Ferreira, Victor S., Robert Slevc, and Erin S. Rogers. 2005. “How Do Speakers Avoid Ambiguous Linguistic Expressions?" Cognition 263-284. https://doi.org/10.1016/j.cognition.2004.09.002

Field, Richard W. 2007. "Pragmatic Failure and the Attribution of Belief." Journal of Philosophical Research 32: 133-143. doi: 10.5840/jpr20073244

Fraser, Bruce. 1990. "Perspectives on Politeness." Journal of Pragmatics 14 (2): 219-236. 
https://doi.org/10.1016/0378-2166(90)90081-N

Fricker, Miranda. 1998. "Rational Authority and Social Power: Towards a Truly Social Epistemology." Proceedings of the Aristotelian Society 98 (2): 159-177.

Fricker, Miranda. 2003. "Epistemic Injustice and a Role for Virtue in the Politics of Knowing." Metaphilosophy 34 (1-2): 154-173. doi: 10.1111/1467-9973.00266

Fricker, Miranda. 2006. "Powerlessness and Social Interpretation." Episteme, A Journal of Social Epistemology: A Journal of Knowledge, Culture and Policy 3 (1-2): 96-108. doi: 10.1353/epi.0.0004

Fricker, Miranda. 2007. Epistemic Injustice. Power \& the Ethics of Knowing. Oxford: Oxford University Press.

Friedrich, James. 1993. "Primary Error Detection and Minimization (PEDMIN) Strategies in Social Cognition: A Reinterpretation of Confirmation Bias Phenomena." Psychological Review 100 (2): 298-319. doi: 10.1037/0033-295X.100.2.298

Furnham, Adrian, and Tracy Ribchester. 1995. "Tolerance of Ambiguity: A Review of the Concept, Its Measurement and Applications." Current Psychology 14 (3): 179-199.

García, Carmen. 1989. “Apologising in English: Politeness Strategies used by Native and Nonnative Speakers." Multilingua 8 (1): 3-20. Doi: https://doi.org/10.1515/mult.1989.8.1.3

Gass, Susan M., and Evangeline M. Varonis. 1991. “Miscommunication in Nonnative Speaker Discourse." In "Miscommunication" and Problematic Talk, edited by Nikolas Coupland, Howard Giles and John M. Wiemann, 121-145. London: Sage.

Goodwin, C. 1986. "Between and within: Alternative Sequential Treatments of Continuers and Assessments." Human Studies 9 (2-3): 205-217. https://doi.org/10.1007/BF00148127

Grimshaw, Allen D. 1980. “Mishearings, Misunderstandings, and Other Nonsuccesses in Talk:

A Plea for Redress of Speaker-oriented Bias." Sociological Inquiry 50 (3-4): 31-74. doi: 
10.1111/j.1475-682X.1980.tb00016.x

Hartmann, Ernest. 1991. Boundaries in the Mind: A New Psychology of Personality. New York: Basic Books.

Hickey, Leo. 1991. "Comparatively Polite People in Britain and Spain." ACIS: Journal of the Association for Contemporary Iberian Studies 4 (2): 2-6.

Hinnenkamp, Volker. 2003. "Misunderstandings: Interactional Structure and Strategic Resources." In Misunderstanding in Social Life: Discourse Approaches to Problematic Talk, edited by Juliane House, Gabriele Kasper and Steven Ross, 57-81. London: Sage.

Hymes, Dell H. 1972. “On Communicative Competence." In Sociolinguistics. Selected Readings, edited by John B. Pride and Janet Holmes, 269-293. Baltimore: Penguin Books.

Ide, Sachiko. 1989. "Formal Forms and Discernment: Two Neglected Aspects of Universals of Linguistic Politeness." $\quad$ Multilingua $8 \quad(2-3): \quad 223-248 . \quad$ doi: https://doi.org/10.1515/mult.1989.8.2-3.223

Ifantidou, Elly. 1992. "Sentential Adverbs and Relevance." UCL Working Papers in Linguistics 4: 193-214.

Ifantidou, Elly. 1993. "Parentheticals and Relevance." UCL Working Papers in Linguistics 5: 193-210.

Ifantidou, Elly. 2001. Evidentials and Relevance. Amsterdam: John Benjamins. Jefferson, Gail. 1972. "Side sequences." In Studies in Social Interaction, edited by David N. Sudnow, 294-338. New York: Free Press.

Jones, Karen. 2012. "The Politics of Intellectual Self-trust." Social Epistemology. A Journal of Knowledge, Culture and Policy 26 (2): 237-251. doi: 10.1080/02691728.2011.652215 Jucker, Andreas H., Sara W. Smith, and Tanja Lüdge. 2003. "Interactive Aspects of Vagueness in Conversation." Journal of Pragmatics 35 (12): 1737-1769. https://doi.org/10.1016/S0378- 
2166(02)00188-1

Kasanga, Luanga A. 2001. "Intercultural Sociolinguistics and Communication Research in South Africa: Its Relevance to Academic Settings and the Service Industry." Southern African Linguistics and Applied Language Studies $19 \quad$ (3-4): 253-273. http://dx.doi.org/10.2989/16073610109486291

Kasanga, Luanga A., and Joy-Christine Lwanga-Lumu. 2007. "Cross-cultural Linguistic Realisation of Politeness: A Study of Apologies in English and Setswana." Journal of Politeness Research. Language, Behaviour, Culture 3 (1): 65-92. https://doi.org/10.1515/PR.2007.004 Kasper, Gabriele. 1997. “Can Pragmatic Competence Be Taught?” (NetWork \#6). Honolulu: University of Hawai'i, Second Language Teaching \& Curriculum Center. http://www.nflrc.hawaii.edu/NetWorks/NW06/

Kataoka, Kuniyoshi. 1995. “Affect in Japanese Women's Letter Writing: Use of Sentence-final Particles Ne and Yo and Orthographic Conventions." Pragmatics 5 (4): 427-453. doi: 10.1075/prag.5.4.02kat

Klayman, Joshua. 1995. "Varieties of Confirmation Bias." In Decision Making from a Cognitive Perspective. The Psychology of Learning and Motivation. Vol. 32, edited by Jerome Busemeyer, Reid Hartie and Douglas L. Medin, 385-418. New York: Academic Press.

Keysar, Boaz. 2007. "Communication and Miscommunication: The Role of Egocentric Processes." Intercultural Pragmatics 4 (4): 71-85. doi: 10.1515/IP.2007.004

Keysar, Boaz, and Anne S. Henly. 2002. "Speakers' Overestimation of their Effectiveness." Psychological Science 13 (3): 207-212. doi: 10.1111/1467-9280.00439

Kunda, Ziva. 1999. Social Cognition: Making Sense of People. Boston: MIT Press.

Leech, Geoffrey. 1983. Principles of Pragmatics. London: Longman.

Lorde, Audre. 1981. "The Uses of Anger." Women's Studies Quarterly 9 (3): 7-10. 
Manes, Joan, and Nessa Wolfson. 1981. "The Compliment Formula." In Conversational Routine. Explorations in Standardized Communication Situations and Prepatterned Speech, edited by Florian Coulmas, 115-132. The Hague: Mouton.

Manji, Rahim, Lois Presser, and Leigh T. Dickey. 2014. "Passivity, Harm, and Injustice." Contemporary Justice Review 17 (1): 47-62. https://doi.org/10.1080/10282580.2014.884788 Mascaro, Olivier, and Dan Sperber. 2009. "The Moral, Epistemic, and Mindreading Components of Children's Vigilance towards Deception." Cognition 112 (3): 367-380. https://doi.org/10.1016/j.cognition.2009.05.012

McCollum, James. 2012. "Hermeneutical Injustice and the Social Sciences: Development Policy and Positional Objectivity." Social Epistemology: A Journal of Knowledge, Culture and Policy 26 (2): 189-200. https://doi.org/10.1080/02691728.2011.652212

McCraw, Benjamin W. 2015. "The Nature of Epistemic Trust." Social Epistemology: A Journal of Knowledge, Culture and Policy 29 (4): 413-430. https://doi.org/10.1080/02691728.2014.971907

McRoy, Susan, and Graeme Hirst. 1995. "The Repair of Speech Act Misunderstanding by Abductive Inference." Computational Linguistics 21 (4): 435-478.

Medina, José. 2011. "The Relevance of Credibility Excess in a Proportional View of Epistemic Injustice: Differential Epistemic Authority and the Social Imaginary." Social Epistemology: A Journal of Knowledge, Culture and Policy 25 (1): 15-35. doi: 10.1080/02691728.2010.534568 Medina, José. 2012. “Hermeneutical Injustice and Polyphonic Contextualism: Social Silences and Shared Hermeneutical Responsibilities." Social Epistemology: A Journal of Knowledge, Culture and Policy 26 (2): 201-220. doi: 10.1080/02691728.2011.652214

Mercier, Hugo, and Dan Sperber. 2011. "Why Do Humans Reason? Arguments for an Argumentative Theory." Behavioral and Brain Sciences 34 (2): 57-111. doi: 


\section{$10.1017 / \mathrm{S} 0140525 \mathrm{X} 10000968$}

Michaelian, Kourken. 2013. "The Evolution of Testimony: Receiver Vigilance, Speaker Honesty and the Reliability of Communication." Episteme 10 (1): 37-59. doi: 10.1017/epi.2013.2 Munroe, Wade. 2016. "Testimonial injustice and Prescriptive Credibility Deficits." Canadian Journal of Philosophy 46 (6): 1-24. https://doi.org/10.1080/00455091.2016.1206791

Mustajoki, Arto. 2012. “A Speaker-oriented Multidimensional Approach to Risks and Causes of Miscommunication." Language and Dialogue 2 (2): 216-246. doi: 10.1075/Id.2.2.03mus Nickerson, Raymond S. 1998. "Confirmation Bias: A Ubiquitous Phenomenon in Many Guises." Review of General Psychology 2 (2): 175-220. http://dx.doi.org/10.1037/1089-2680.2.2.175 Olshtain, Elite, and Andrew D. Cohen. 1990. "The Learning of Complex Speech Act Behaviour." TESL Canada Journal 7 (2): 45-65.

Origgi, Gloria. 2012. "Epistemic Injustice and Epistemic Trust." Social Epistemology: A Journal of Knowledge, Culture and Policy $26 \quad$ (2): 221-235. https://doi.org/10.1080/02691728.2011.652213

Padilla Cruz, Manuel. 2012. “Epistemic Vigilance, Cautious Optimism and Sophisticated Understanding." Research in Language 10 (4): 365-386. https://doi.org/10.2478/v10015-0110040-y

Padilla Cruz, Manuel. 2013. "Understanding and Overcoming Pragmatic Failure in Intercultural Communication: From Focus on Speakers to Focus on Hearers." International Review of Applied Linguistics in Language Teaching 51 (1): 23-54. https://doi.org/10.1515/iral-20130002

Padilla Cruz, Manuel. 2014. "Pragmatic Failure, Epistemic Injustice and Epistemic Vigilance." Language \& Communication 39: 34-50. https://doi.org/10.1016/j.langcom.2014.08.002 Padilla Cruz, Manuel. 2015. "On the Role of Vigilance in the Interpretation of Puns." Humor. 
International Journal of Humor Research 28 (3): 469-490. https://doi.org/10.1515/humor2015-0068

Padilla Cruz, Manuel. 2016. "Vigilance Mechanisms in Interpretation: Hermeneutical Vigilance." Studia Linguistica Universitatis lagellonicae Cracoviensis 133 (1): 21-29. doi: 10.4467/20834624SL.15.001.4890.

Padilla Cruz, Manuel. 2017a. "Interlocutors-related and Hearer-specific Causes of Misunderstanding: Processing Strategy, Confirmation Bias and Weak Vigilance." Research in Language 15 (1): 11-36. doi: 10.1515/rela-2017-0006

Padilla Cruz, Manuel. 2017b. "On the Usefulness of the Notion of 'Conceptual Competence Injustice' to Linguistic Pragmatics." Social Epistemology Review and Reply Collective 6 (4): 1219. http://wp.me/p1Bfg0-3y8

Padilla Cruz, Manuel. 2017c. “Conceptual Competence Injustice and Relevance Theory, a Reply to Derek Anderson." Social Epistemology Review and Reply Collective 6 (12): 39-50. https://wp.me/p1Bfg0-3RS

Podosky, Paul-Mikhail Catapang, and William Tuckwell. 2017. "There Is No Such Thing as Conceptual Competence Injustice: A Response to Anderson and Cruz". Social Epistemology Review and Reply Collective 6 (11): 23-32.

Pohlhaus, Gaile Jr. 2014. “Discerning the Primary Epistemic Harm in Cases of Testimonial Injustice." Social Epistemology: A Journal of Knowledge, Culture and Policy 28 (2): 99-114. https://doi.org/10.1080/02691728.2013.782581

Reynolds, Mike. 1995. "Where the Trouble Lies: Cross-cultural Pragmatics and Miscommunication." Papers and Studies in Contrastive Linguistics 30: 5-15.

Riley, Philip. 1989. "Well Don't Blame Me! On the Interpretation of Pragmatic Errors." In Contrastive Pragmatics, edited by Wieslaw Oleksy, 231-249. Amsterdam: John Benjamins. 
Riley, Philip. 2006. "Self-expression and the Negotiation of Identity in a Foreign Language." International Journal of Applied Linguistics 16 (3): 295-318. doi: 10.1111/j.14734192.2006.00120.x

Riggs, Wayne. 2012. “Culpability for Epistemic Injustice: Deontic or Aretetic?" Social Epistemology: A Journal of Knowledge, Culture and Policy 26 (2): 149-162. https://doi.org/10.1080/02691728.2011.652210

Romdenh-Romluc, Komarine. 2016. "Hermeneutical Injustice: Blood-sports and the English Defence League." Social Epistemology: A Journal of Knowledge, Culture and Policy 30 (5): 592610. https://doi.org/10.1080/02691728.2016.1172363

Ryan, Jonathon, and Roger Barnard. 2009. “"Who Do You Mean?" Investigating Miscommunication in Paired Interactions." The TESOLANZ Journal 17: 44-62. https://hdl.handle.net/10289/3732

Schegloff, Emanuel A. 1982. “Discourse as an Interactional Achievement: Some Uses of uh huh and Other Things that Come between Sentences." In Georgetown University Roundtable in Language and Linguistics 1981. Analysing Discourse: Text and Talk, edited by Deborah Tannen, 71-93. Washington: Georgetown University Press.

Searle, John. 1969. Speech Acts: An Essay in the Philosophy of Language. Cambridge: Cambridge University Press.

Searle, John. 1975. "Indirect Speech Acts." In Syntax and Semantics. Vol. 3: Speech Acts, edited by Peter Cole and Jerry Morgan, 59-82. New York: Academic Press.

Sherman, Benjamin R. 2016. “There's No (Testimonial) Justice: Why Pursuit of a Virtue Is Not the Solution to Epistemic Injustice." Social Epistemology: A Journal of Knowledge, Culture and Policy 30 (3): 229-250. https://doi.org/10.1080/02691728.2015.1031852

Shintel, Hadas, and Boaz Keysar. 2009. "Less Is More: A Minimalist Account of Joint Action in 
Communication." Topics in Cognitive Science 1: 260-273. doi: 10.1111/j.17568765.2009.01018.x

Smith, Janet S. 1992. "Women in Charge: Politeness and Directives in the Speech of Japanese Women." Language in Society 21 (1): 59-82. doi: http://www.jstor.org/stable/4168311 Spencer-Oatey, Helen, ed. 2000. Culturally Speaking: Managing Rapport through Talk across Cultures. London: Continuum.

Sperber, Dan. 1994. "Understanding Verbal Understanding." In What Is Intelligence? edited by Jean Khalfa, 179-198. Cambridge: Cambridge University Press.

Sperber, Dan. 1996. Explaining Culture. A Naturalistic Approach. Oxford: Blackwell. Sperber, Dan. 1997. "Intuitive and Reflective Beliefs." Mind \& Language 12 (1): 67-83. doi: 10.1111/j.1468-0017.1997.tb00062.x

Sperber, Dan. 2013. "Speakers Are Honest because Hearers Are Vigilant. Reply to Kourken Michaelian." Episteme 10 (1): 61-71. doi: 10.1017/epi.2013.7

Sperber, Dan, and Deirdre Wilson. 1986. Relevance. Communication and Cognition. Oxford: Blackwell.

Sperber, Dan, and Deirdre Wilson. 1995. Relevance. Communication and Cognition. $2^{\text {nd }}$ ed. Oxford: Blackwell.

Sperber, Dan, and Deirdre Wilson. 1997. "The Mapping between the Mental and the Public Lexicon." UCL Working Papers in Linguistics 9: 107-125.

Sperber, Dan, and Deirdre Wilson. 2015. "Beyond Speaker's Meaning." Croatian Journal of Philosophy 15 (44): 117-149.

Sperber, Dan, Fabrice Clément, Christophe Heintz, Olivier Mascaro, Hugo Mercier, Gloria Origgi, and Deirdre Wilson. 2010. “Epistemic Vigilance." Mind \& Language 25 (4): 359-393. doi: 10.1111/j.1468-0017.2010.01394.x 
Tannen, Deborah. 1981. "Indirectness in Discourse: Ethnicity as Conversational Style." Discourse Processes 4 (3): 221-238. doi: https://doi.org/10.1080/01638538109544517

Tannen, Deborah. 1984. "The Pragmatics of Cross-cultural Communication." Applied Linguistics 5 (3): 188-195. doi: 10.1093/applin/5.3.189

Tannen, Deborah. 1987. That's Not What I Meant! How Conversational Style Makes or Breaks Your Relations with Others. London: Virago Press.

Tannen, Deborah. 1990. You Just Don't Understand. Women and Men in Conversation. London: Virago Press.

Thomas, Jenny. 1983. “Cross-cultural Pragmatic Failure." Applied Linguistics 4 (2): 91-112. doi: 10.1093/applin/4.2.91

Tran, Giao Q. 2006. The Nature and Conditions of Pragmatic and Discourse Transfer Investigated through Naturalized Role-play. Muenchen: Lincom.

Verdonik, Darinka. 2010. "Between Understanding and Misunderstanding." Journal of Pragmatics 42 (5): 1364-1379. doi: 10.1016/j.pragma.2009.09.007

Weigand, Edda. 1999. “Misunderstanding: The Standard Case." Journal of Pragmatics 31 (6): 763-785. doi: 10.1016/S0378-2166(98)00068-X

Wenger, Etienne. 1998. Communities of Practice. Learning, Meaning and Identity. Cambridge: Cambridge University Press.

Wharton, Tim. 2009. Pragmatics and Non-verbal Communication. Cambridge: Cambridge University Press.

Wierzbicka, Anna. 1991. Cross-Cultural Pragmatics: The Semantics of Human Interaction. Berlin: Mouton de Gruyter.

Wilson, Deirdre. 1999. "Metarepresentation in Linguistic Communication." UCL Working Papers in Linguistics 11: 127-161. 
Wilson, Deirdre, and Dan Sperber. 1993. "Linguistic Form and Relevance." Lingua 90 (1-2): 126. doi: 10.1016/0024-3841(93)90058-5

Wilson, Deirdre, and Dan Sperber. 2002. "Relevance Theory." UCL Working Papers in Linguistics 14: 249-287.

Wilson, Deirdre, and Dan Sperber. 2004. "Relevance Theory." In The Handbook of Pragmatics, edited by Larry Horn and Gregory Ward, 607-632. Oxford: Blackwell.

Wilson, Deirdre, and Tim Wharton. 2006. "Relevance and Prosody." Journal of Pragmatics 38 (10): 1559-1579. doi: 10.1016/j.pragma.2005.04.012

Wolfson, Nessa, and Joan Manes. 1980. "The Compliment as a Social Strategy." Papers in Linguistics 13: 391-410.

Yus Ramos, Francisco. 1999a. "Towards a Pragmatic Taxonomy of Misunderstandings." Revista Canaria de Estudios Ingleses 38: 217-239.

Yus Ramos, Francisco. 1999b. "Misunderstandings and Explicit/Implicit Communication." Pragmatics 9 (4): 487-517. 